\title{
Airborne Contamination of Forest Soils by Carbonaceous Particles from Industrial Coal Processing
}

\author{
Michael W.I. Schmidt,* Heike Knicker, Patrick G. Hatcher, and Ingrid Kögel-Knabner
}

\begin{abstract}
In the German Ruhr-area industrial coal processing emitted large amounts of carbonaceous particles for a century until 1970. Our objectives were to detect the presence of airborne carbonaceous particles and assess their impact on the chemical structure of soil organic matter in two forest soils (Podzols) with potential sources of carbonaceous particles approximately 10 to $30 \mathrm{~km}$ away. Contamination was not visible macroscopically. Organic matter was characterized in bulk soils and in particle-size separates by elemental analysis, magnetic susceptibility measurement, reflected light microscopy, and ${ }^{13} \mathrm{C}$ solidstate nuclear magnetic resonance (NMR) spectroscopy. Organic and mineral horizons contained carbonaceous particles including char, coke, and bituminous coal from coal combustion, coking, coal processing, and steel production. In the organic horizons of both soils we observed a material high in magnetic susceptibility (max. $109 \times$ $10^{-8} \mathrm{~m}^{3} \mathrm{~kg}^{-1}$ ), whereas in the mineral horizons only the Podzol with an intense intermixing moder-type humus had high magnetic susceptibly. This Aeh horizon was extremely rich in organic carbon (139.4 g organic $\mathrm{C} \mathrm{kg}^{-1}$ ), concentrated in the 20 to $2000 \mu \mathrm{m}$ size separates. In the second Podzol, like in many natural soils, $C$ concentrations were largest in the $<20 \mathrm{~mm}$ separates. Bloch decay ${ }^{13} \mathrm{C}$ magic angle spinning (MAS) NMR spectroscopy revealed a highly aromatic structure of the carbonaceous particles. Airborne carbonaceous particles formed a macroscopically indistinguishable mixture with natural soil organic matter and could be present in many soils neighboring industrialized areas.
\end{abstract}

$\mathrm{E}$ MISSIONS of carbonaceous particles, such as char, coke, and soot, originate from fossil fuel combustion, coking, steel smelters, or other industrial processes. These emissions may be ubiquitously dispersed, transported via the atmosphere, and probably accumulate in the soils of industrialized areas. In the atmosphere of urban areas, soot-like carbonaceous particles can contribute up to $30 \%$ of the total mass to the suspended particulate matter (Elbers et al., 1990; Schultz, 1993), while in remote locations, contributions often are less than 1\% (Rau and Khalil, 1993). Many of these carbonaceous particles consist of highly condensed aromatic structures that probably resist degradation for decades, centuries, or even longer, and consequently may accumulate in soils and sediments (Shindo, 1991; Shneour, 1966; Schmidt and Noack, 2000).

Previous work focused on carbonaceous particles in sediments (e.g., in lakes and marine systems) (Karls and Christensen, 1998; Wik and Renberg, 1996). Sediments and soils share common features but also are strikingly different (Hedges and Oades, 1997). Soil horizons are

M.W.I. Schmidt, H. Knicker, and I. Kögel-Knabner, Dep. of Soil Science, Technische Universität München, D-85350 Freising-Weihenstephan, Germany; P.G. Hatcher, Dep. of Chemistry, Ohio State Univ., 100 West 18th Ave., Columbus OH 43210. M.W.I. Schmidt, present address: Dep. of Geography, Univ. of Cologne, Zuelpicher Str. 49a, 50674 Cologne, Germany. Received 21 June 1999. *Corresponding author (mwi.schmidt@uni-koeln.de).

Published in J. Environ. Qual. 29:768-777 (2000). continuously reworked by bioturbation (e.g., by earthworms and roots), while sediments often record the information in unmixed layers. Catchment areas of soils are generally smaller, thus archiving a more local history. Numerous studies were published on terrestrial transported carbonaceous particles, such as coal or ash layers, in industrial sites or applied as soil amendments. However, studies on airborne carbonaceous particles in soils are sparse. In organic layers of soils and peats, Thompson and Oldfield (1986) found indirect evidence for the presence of carbonaceous particles, probably originating from industrial processes, by measuring magnetic susceptibility. Using microscopy, Wik and Renberg (1996) identified carbonaceous particles from coal combustion in Swedish forest soils. In mineral horizons, fossil fuel-derived organic compounds were detected by isotopic techniques (Lichtfouse et al., 1997). Recently we could identify and quantify noncombusted lignite dust in soils by a combination of spectroscopic and isotopic techniques (Rumpel et al., 1998; Schmidt et al., 1996). Airborne lignite dust contributed up to 35 $\mathrm{kg} \mathrm{m}^{-2}$ to the plowed horizon of an agricultural field, thus accounting for $80 \%$ of the total organic carbon. Combusted particles contributed only minor proportions to the identified organic particles, probably due to the proximity to a source of lignite dust. However, in other highly industrialized areas, emissions often contribute charred particles (e.g., coke, soot, and char) that have not yet been identified in mineral horizons.

We address an important gap in our understanding of the importance of airborne carbonaceous particles in forest soils of industrialized regions. The objective of this study was to identify carbonaceous particles from coal industries in two forest Podzols, situated 10 to 30 $\mathrm{km}$ from the nearest industrial source. The carbonaceous particles probably had been deposited before industrial emissions significantly decreased since the 1970 s (Blaurock, 1990). Content and chemical structure of the organic matter were studied in bulk soils and particlesize separates of several horizons by a suite of complementary methods: elemental analysis, magnetic susceptibility measurement, microscopy, and ${ }^{13} \mathrm{C}$ solid-state NMR.

\section{MATERIALS AND METHODS}

\section{Sampling Sites}

Two Haplic Podzols, suspected to contain airborne carbonaceous particles from coal industries, were sampled in the formerly highly industrialized Ruhr-area (Fig. 1) in 1995 and 1996. Since the 1970s filter techniques improved and emissions decreased, namely those from coal processing, combustion, coking, and metallurgic processes. Prior to that time many of these industries produced carbonaceous particles that proba-

Abbreviations: MAS, magic angle spinning; NMR, nuclear magnetic resonance; $\mathrm{CP}$, cross-polarization. 
bly have accumulated in the soils of the Ruhr-area for decades (Blaurock, 1990). Emissions from upwind industries probably affected both investigated Podzols (Fig. 1). However, the presence of coal dust, coke, or char was not visible by macroscopic observation. The Podzol Grafenwald was collected north of Bottrop in the forest of Grafenwald. The potential sources of emissions had been power plants combusting coal, coking plants, and steel smelters in the towns of Dinslaken (W), Oberhausen (SW), Bottrop (S) and Gelsenkirchen (SE and $\mathrm{E}$ ), all about $10 \mathrm{~km}$ away, and a mining deposit (Halde Haniel), situated about $1 \mathrm{~km}$ south of the sampling site. The Podzol Flaesheim was situated on the northern border of the industrialized area in the forest of Flaesheim, south of Haltern. Here potential sources of emissions had been at least $30 \mathrm{~km}$ away. The Podzols were chosen to correspond as close as possible regarding pedogenesis, texture, vegetation, soil type, and climate. However, humus types were different. The Podzol Grafenwald was covered by mixed deciduous and spruce forest with a moder humus, and the Podzol Flaesheim was under a spruce stand with mor humus. Mor humus is less intermixed with mineral material than moder humus. The vegetation of both Podzols had been forest since the beginning of the 20th century.

We sampled each Podzol in triplicate and combined subsamples. Organic horizons were sampled in a radial sampling scheme (15 $\mathrm{m}$ diameter), with each subsite covering about $4 \mathrm{~m}^{2}$. Mineral horizons were sampled in the pits $(1.5 \times 4 \mathrm{~m})$, each location representing about $0.3 \mathrm{~m}^{2}$ for the A horizons and $0.1 \mathrm{~m}^{2}$ for the subsoils.

\section{Sample Pretreatment and Particle-Size Separation}

Soil description, sampling, and classification were performed according to established procedures (FAO, 1994). Horizons were designated according to the German Soil Survey Description (AG-Boden, 1994). Bulk densities of the mineral horizons were determined gravimetrically in standardized steel rings after drying at $105^{\circ} \mathrm{C}$. Roots and visible plant remains were mechanically removed from mineral soil horizons. After freeze-drying, soil aggregates were crushed and the separate $>2 \mathrm{~mm}$ was removed by dry sieving. For chemical analysis an aliquot was ground in a ball mill for $10 \mathrm{~min}$. The $\mathrm{pH}$ was measured with a glass electrode in the supernatant of a mixture of $0.01 \mathrm{M} \mathrm{CaCl}_{2}$ and soil (2.5:1 based on mass).

Two particle-size separation procedures were used for the two Podzols. All mineral horizons were analyzed for their particle-size distribution (Table 1) following the standard pipette-sieve method (Gee and Bauder, 1986). From four of these horizons (i.e., the two Aeh horizons and the $\mathrm{Bh}$ and Bhs horizon, respectively) we isolated seven particle-size separates, obtained by a combination of wet sieving and sedimentation (Table 3) after complete dispersion by ultrasound (Schmidt et al., 1999a,b). Briefly, we calibrated the ultrasonic energy of an ultrasonic titanium probe with a diameter of 19 $\mathrm{mm}$ (Labsonic U, Braun Melsungen, Germany) and applied $440 \mathrm{~J}$ per $\mathrm{ml}$ of suspension to obtain complete dispersion of the samples. By wet sieving, the suspension was separated into three sand separates ( 630 to $2000 \mu \mathrm{m}, 200$ to $630 \mu \mathrm{m}$, and 63 to $200 \mu \mathrm{m})$. The clay separate $(<2 \mu \mathrm{m})$ and three silt separates ( 20 to $63 \mu \mathrm{m}, 6$ to $20 \mu \mathrm{m}$, and 2 to $6 \mu \mathrm{m}$ ) were obtained by gravity sedimentation and were recovered from

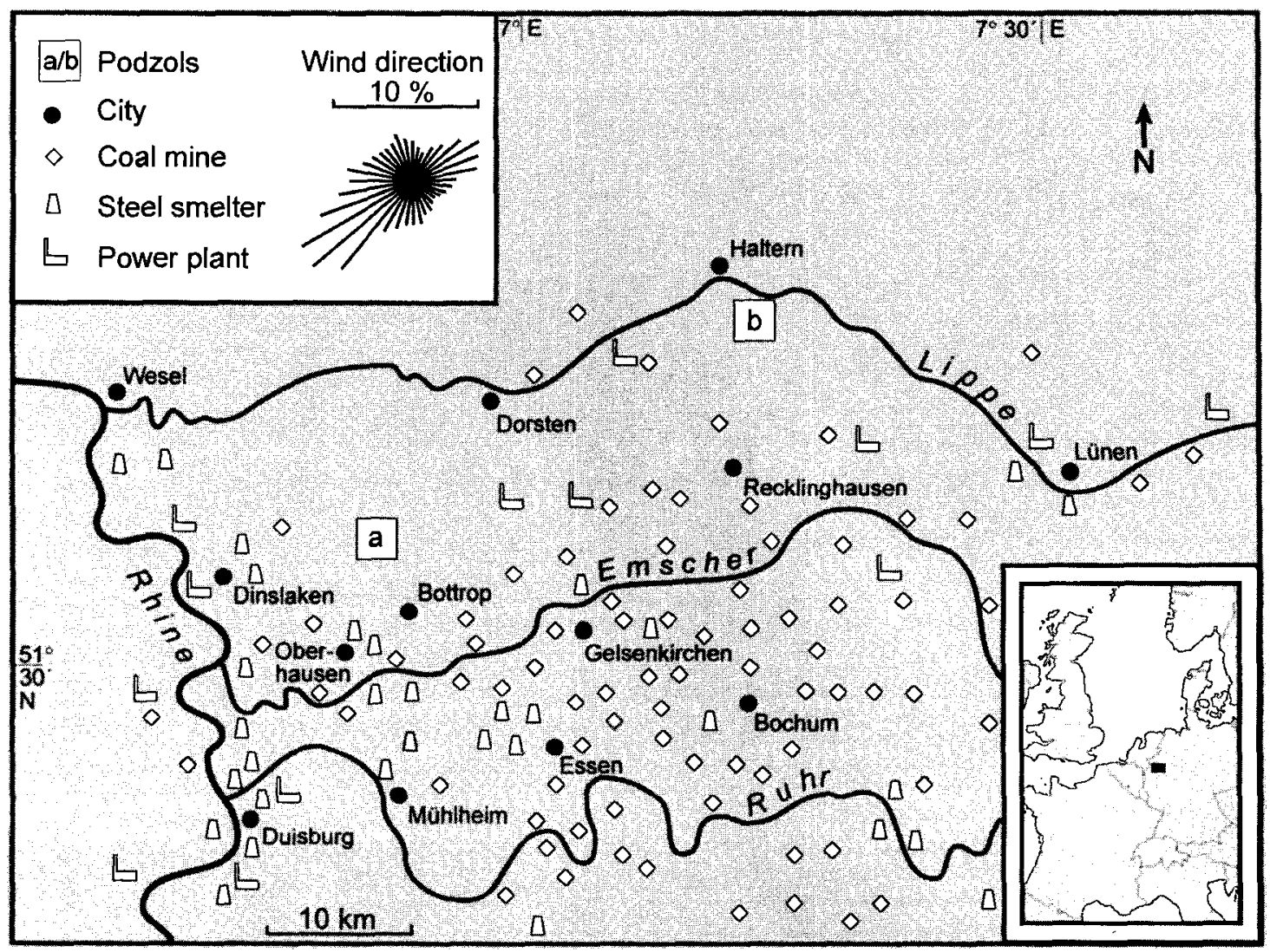

Fig. 1. Studied sites in the Ruhr-area, Germany. Sampled sites are (a) Podzol Grafenwald and (b) Podzol Flaesheim and potential sources of organic particles from coal processing industries (e.g., coal mines, steel smelters, and power plants) that existed between 1850 and 1990 were compiled after Cornelsen (1991). Wind directions are reported for Bottrop and are based on the annual average of 4 to 5 yr (MURL, 1989). 
Table 1. Description of the Haplic Podzols (FAO, 1994).

\begin{tabular}{|c|c|c|c|c|c|c|c|c|c|c|}
\hline Horizon $\dagger$ & Depth & pH & $\mathbf{C}_{\text {org }}$ & Total N & $\mathbf{C : N}$ & Sand & Silt & Clay & $\begin{array}{c}\text { Bulk } \\
\text { density }\end{array}$ & $\begin{array}{c}\text { Magnetic } \\
\text { susceptibility }\end{array}$ \\
\hline & $\mathbf{c m}$ & & $\longrightarrow$ & $-1 \longrightarrow$ & & $\longrightarrow$ & 1ass $\%$ & - & $\mathrm{Mg} \mathrm{m}^{-3}$ & $10^{-8} \mathrm{~m}^{3} \mathrm{~kg}^{-1}$ \\
\hline \multicolumn{11}{|l|}{ Flaesheim } \\
\hline L & +13 & - & 482.0 & 13.0 & 37 & - & - & - & - & 4 \\
\hline Of & +10 & - & 334.1 & 13.5 & 25 & - & - & - & - & 61 \\
\hline $\mathbf{O h}$ & +5 & - & 258.0 & 9.7 & 27 & - & - & - & - & 109 \\
\hline Aeh & 12 & 3.1 & 14.5 & 0.4 & 36 & 92.4 & 6.5 & 1.3 & 1.40 & 1 \\
\hline Ae & 25 & 3.3 & 3.1 & 0.2 & 16 & 92.2 & 8.5 & 0.3 & 1.41 & 1 \\
\hline Bh & 31 & 2.9 & 34.5 & 1.0 & 35 & 87.1 & 8.9 & 4.1 & 1.23 & 1 \\
\hline Bs & 35 & 3.4 & 13.6 & 0.6 & 23 & 85.0 & 11.4 & 3.7 & 1.28 & i \\
\hline Bsv & 140 & 4.0 & 1.2 & $<\mathbf{0 . 1}$ & - & 95.9 & 2.3 & 1.8 & - & - \\
\hline Bv & $>140$ & 4.2 & 0.5 & $<\mathbf{0 . 1}$ & - & 96.1 & 1.2 & 0.6 & 1.34 & - \\
\hline \multicolumn{11}{|l|}{ Grafenwald } \\
\hline L & +3 & - & 480.4 & 13.2 & 36 & - & - & - & - & $\mathbf{1 1}$ \\
\hline Of & +1 & - & 465.1 & 17.7 & 26 & - & - & - & - & 52 \\
\hline $\mathbf{O h}$ & +0.5 & - & 426.2 & 17.4 & 25 & - & - & - & - & 103 \\
\hline Aeh bulk & 8 & 3.1 & 139.4 & 5.8 & 24 & 73.7 & 20.9 & 5.9 & 0.80 & 81 \\
\hline Aeh floating & & - & 344.9 & 14.9 & 23 & \multirow{2}{*}{\multicolumn{3}{|c|}{$\begin{array}{r}-14.8- \\
\\
\end{array}$}} & - & - \\
\hline Aeh sinking & & - & 104.0 & 4.2 & 25 & & & & - & - \\
\hline $\mathbf{A e}$ & 17 & 3.2 & 30.1 & 1.0 & 30 & 91.0 & 8.8 & 1.3 & 1.32 & 4 \\
\hline Bhs & 22 & 3.2 & 17.0 & 0.6 & 28 & 80.3 & 14.8 & 4.8 & 1.45 & 1 \\
\hline $\mathbf{B v}$ & 70 & 4.1 & 9.2 & 0.5 & 18 & 79.8 & 16.4 & 3.9 & 1.48 & 2 \\
\hline $\mathrm{Cv}$ & $>70$ & 4.1 & 0.7 & $<\mathbf{0 . 1}$ & - & 82.8 & 15.4 & 1.9 & - & - \\
\hline
\end{tabular}

$\dagger$ Horizon designations were according to AG-Boden (1994).

¥ Results obtained by standard particle size analysis (Gee and Bauder, 1986).

- Not determined.

the suspensions by filtration (cellulose nitrate, $0.45 \mu \mathrm{m}$ ). Alterations of the chemical structure of organic matter due to ultrasonication and subsequent ball milling were expected to be small (Schmidt et al., 1997a).

When we prepared a suspension from the Aeh horizon of the Podzol Grafenwald with water, two subfractions formed. One fraction sunk while the other kept floating on the water as a deep-black foam, despite vigorously stirring and mixing in an ultrasonic bath. We had not observed such a floating fraction in soils or sediments before, so we isolated the floating and the sinking fraction manually and dried them for further analysis.

\section{Elemental Analysis}

Carbon and nitrogen concentrations of the bulk soils and the various fractions were determined in duplicate with a Leco CNS 2000 (Leco, Kirchheim, Germany). The concentration of dissolved organic carbon was determined with a Shimadzu TOC 5050 Analyzer (Shimadzu, Duisburg, Germany).

\section{Carbon-13 Nuclear Magnetic Resonance Spectroscopy}

The solid-state ${ }^{13} \mathrm{CNMR}$ spectra were obtained on a Bruker MSL 100 (Bruker, Karlsruhe, Germany) (25.178 MHz) (Dep. of Biophysics, Univ. of Regensburg) and a Chemagnetics

Table 2. Chemical shift assignment of peaks in the solid-state ${ }^{13} \mathrm{C}$ CP MAS NMR spectra (referenced to tetramenthylsilane $=\mathbf{0}$ ppm) (Lüdemann and Nimz, 1973; Wilson, 1987).

Chemical shift

range (ppm)

220 to 160

160 to 140

140 to 120

120 to 100

100 to 60

60 to 45

45 to -10
Assignment

Carboxyl/carbonyl/amide carbons

Aromatic COR or CNR groups

Aromatic C-H carbons, guaiacyl C-2, C-6 in lignin, olefinic carbons

Anomeric carbon of carbohydrates, C-2, C-6 of syringyl units in lignin

O-alkyl of carbohydrates and alcohols, $C$ - $\alpha$ of some amino acids

Methoxyl groups, $C-\alpha$ of most amino acids

$2^{\circ}, 3^{\circ}$, and $4^{\circ}$ carbons in alkyl structures
M-100 (Chemagnetics, Fort Collins, CO) (25.035 MHz) (Fuel Science Dep., Pennsylvania State Univ.). The cross-polarization (CP) and MAS techniques (Schaefer and Stejskal, 1976) were applied with a spinning speed of 3.5 and $4 \mathrm{kHz}$, respectively. The ${ }^{13} \mathrm{C}$ CPMAS NMR experiments were carried out with a contact time of $1.0 \mathrm{~ms}$, a $90^{\circ}{ }^{1} \mathrm{H}$-pulse width of $6.6 \mathrm{~ms}$ and a pulse delay of 100 to $600 \mathrm{~ms}$. Before Fourier transformation, we applied line broadenings between 20 and $100 \mathrm{~Hz}$. The ${ }^{13} \mathrm{C}$ Bloch decay NMR spectra were obtained from a Bruker DSX 200 operating at a frequency of $50.3 \mathrm{MHz}$. A ${ }^{13} \mathrm{C}$ pulse width of $4 \mu \mathrm{s}$ and a pulse delay of $60 \mathrm{~s}$ was used. Between 850 and 2700 scans were accumulated. A line broadening of 100 and $150 \mathrm{~Hz}$ was applied before Fourier transformation. A background signal occurring between 200 and $0 \mathrm{ppm}$ and peaking at $110 \mathrm{ppm}$ was observed. Its contribution to the total signal intensity of the spectrum was determined by obtaining spectra from the rotor without sample. Using the subtraction routine of the instrument, an appropriate amount of signal was subtracted from each Bloch decay spectrum.

The ${ }^{13} \mathrm{C}$ chemical shifts (Table 2) are reported relative to tetramethylsilane $(=0 \mathrm{ppm})$. For the relative intensity distribution of the solid-state ${ }^{13} \mathrm{C}$ CPMAS NMR, the precision is, depending on the signal to noise ratio, approximately $10 \%$ of the signal intensity. However, for spectra with low signal to noise ratios, higher deviations can occur for the regions 220 to $160 \mathrm{ppm}$ and 45 to $-10 \mathrm{ppm}$ (Knicker, 1993). To increase the signal to noise ratio and thus to improve the resolution of the spectra, all bulk and particle-size separates from mineral horizons were treated with hydrofluoric acid (HF 10\%) prior to NMR analysis (Schmidt et al., 1997b). This study indicated that chemical alterations due to HF treatment were small.

\section{Magnetic Susceptibility}

The magnetic susceptibility was measured in $5 \mathrm{~cm}^{3}$ tubes at room temperature with a FMA 5000 instrument (Forgenta $\mathrm{GmbH}$, Berlin, Germany) and mass was determined gravimetrically. Results were calibrated against a Kappa-Bridge KY-2 (Advanced Geoscience Instruments, Brno, Czech Republic) and reported as mass- specific magnetic susceptibility $\left(10^{-8}\right.$ $\left.\mathrm{m}^{3} \mathrm{~kg}^{-1}\right)$. 


\section{Reflected Light Microscopy}

Samples for microscopic analysis were prepared by first embedding the sample in a cylindrical mold of polyester resin (Epolite 53/3 epoxy resin, Hexcel, Chatsworth, CA), leaving a cavity $(5 \mathrm{~mm} \times 15 \mathrm{~mm} \times 25 \mathrm{~mm})$ on the center top. The sample was mixed with the resin within the cavity and allowed to set. The surface was polished and examined microscopically in reflected light within oil immersion using a Zeiss Axiophot microscope (Zeiss, Jena, Germany).

\section{RESULTS AND DISCUSSION Physical Characteristics and Elemental
Composition}

\section{Bulk Soils}

The characteristic features of both Podzols were albic A horizons (Aeh, Ae) and spodic B horizons where humic material (Bh), sesquioxidic material (Bs), or both (Bhs) accumulated. Both Podzols had a sandy texture (Table 1) throughout the profile (85 to $96 \%$ and 73 to $91 \%$ sand, respectively) with characteristic, elevated silt and clay contents in the spodic horizons. The Aeh horizon from the Podzol Grafenwald contained more clay and silt than the Aeh horizon from the Podzol Flaesheim, but the texture of the spodic horizons was rather similar. Bulk densities and $\mathrm{pH}$ varied within the range expected for Podzols under forest (Rehfuess, 1990) and revealed no differences between the two soils. Only the bulk density of the Aeh horizon from the Podzol Grafenwald was considerably lower $\left(0.80 \mathrm{Mg} \mathrm{m}^{-3}\right)$ compared with the corresponding horizon of Podzol Flaesheim $\left(1.40 \mathrm{Mg} \mathrm{m}^{-3}\right)$, indicating the presence of material with unusually low density.

In the organic layers (L, Of, Oh) of both Podzols carbon concentrations and C:N ratios generally decreased with depth (Table 1), indicating an increasing decomposition of organic matter. Compared with other Podzols (Rehfuess, 1990), carbon and nitrogen concentrations were slightly lower in the organic horizons. Mineral layers of the Podzol Flaesheim showed characteristic low carbon and nitrogen concentrations in the albic horizons (Aeh: $14.5 \mathrm{~g} \mathrm{C} \mathrm{kg}^{-1}$ air dry soil and $0.4 \mathrm{~g} \mathrm{~N}$ $\mathrm{kg}^{-1}$, respectively), whereas spodic horizons contained more organic matter (Bh: 34.5 and Bs: $13.6 \mathrm{~g} \mathrm{C} \mathrm{kg}^{-1}$ ). Variations in organic matter concentration between the spodic B horizons of Podzol Flaesheim and Podzol Grafenwald (Bhs: $17.0 \mathrm{~g} \mathrm{C} \mathrm{kg}^{-1}$ ) probably can be explained by the different pedogenetic horizons. In summary, the elemental composition of the different horizons varies within the range expected for Podzols.

In contrast, in the Aeh horizon of the Podzol Grafenwald, concentrations of organic carbon $\left(139.4 \mathrm{~g} \mathrm{C} \mathrm{kg}^{-1}\right)$ and nitrogen $\left(5.8 \mathrm{~g} \mathrm{~N} \mathrm{~kg}^{-1}\right)$ were extremely large compared with other Podzols. For example, compared with the Podzol Flaesheim the carbon concentration was greater by a factor of 10 and nitrogen concentration by a factor of 15 . Taking into account bulk densities, differences were smaller but still striking: carbon content was higher by a factor of six and nitrogen content by a factor of eight. This was similar for the underlying
Ae horizon. These large carbon and nitrogen concentrations could not be explained by natural organic matter, because visible roots and plant material were removed prior to analysis. One possible explanation for the large concentrations of organic matter was the presence of a material, rich in carbon and nitrogen, which is not native to this Podzol. When we prepared a suspension from the Aeh horizon of the Podzol Grafenwald, two fractions formed. One typically sank after stirring, whereas the other remained floating despite vigorous mixing. We concluded that the floating fraction might contain a component not native to soils and so we isolated and analyzed the floating and sinking fractions. The floating fraction was extremely rich in organic matter (C: 344.9 $\mathrm{g} \mathrm{kg}^{-1}$ ) compared with the sinking fraction $(104.0 \mathrm{~g}$ $\mathrm{kg}^{-1}$ ). Thus, the material present in the floating fraction probably contributed to the large carbon and nitrogen concentrations found in the Aeh horizon of the Podzol Grafenwald. However, the nature and source of this organic matter remained unclear. It could be airborne carbonaceous particles from fossil fuel combustion or other industrial processes. Airborne particles should be silt size, which would be characteristic for wind transport. Thus, investigating individual particle-size separates could provide further information.

\section{Particle-Size Separates}

Table 3 gives the results obtained for the particle-size separates of the Aeh, Bh, and Bhs horizons of both Podzols using ultrasonic dispersion. Mass proportions of the separates corresponded well with those obtained by standard particle-size analysis (Table 1), except for slightly smaller yields for sand separates. This indicates a more effective dispersion of sand particles by ultrasound compared with standard analysis and is common (Schmidt et al., 1999a,b). The separates revealed clear patterns for particle-size distribution, with only minor variations between $\mathrm{A}$ and $\mathrm{B}$ horizons as well as between the two Podzols. Sand size particles dominated, whereas $<20 \mu \mathrm{m}$ sized particles contributed only little ( $\leq 11.2 \%$ ) to the total soil mass. Carbon and nitrogen concentrations show opposite trends, the with largest concentrations in clay, fine, and medium silt separates, except for the Aeh horizon of the Podzol Grafenwald, which will be discussed later. Despite their low mass, these three separates contributed the majority to the total soil organic matter, both for organic carbon (79.2 to $95.7 \%$ ) and for nitrogen ( 86.9 to $96.6 \%$ ). Compared with previous studies on size separates summarized by Christensen (1992), the observed pattern can be considered to be typical for sandy soils. In these studies carbon to nitrogen ratios $(\mathrm{C}: \mathrm{N})$ typically decreased from coarse to fine separates consistently. Also, in the Podzols studied here, $\mathrm{C}: \mathrm{N}$ ratios were lowest in the clay separates, although C:N ratios could not be calculated for the $>20 \mu \mathrm{m}$ separates due to their low nitrogen concentrations.

While carbon and nitrogen concentrations and distributions in the Aeh and $\mathrm{Bh} / \mathrm{Bh}$ s horizon seemed to follow characteristic patterns common for sandy soils, the Aeh horizon of the Podzol Grafenwald showed a completely 
Table 3. Mass distribution, concentration and distribution of carbon and nitrogen in the Podzols for the particle size separates of different horizons.

\begin{tabular}{|c|c|c|c|c|c|c|}
\hline \multirow[t]{2}{*}{ Horizon $\dagger$} & \multirow{2}{*}{$\begin{array}{c}\text { Mass }+ \\
\begin{array}{c}\% \text { of } \\
\text { bulk }\end{array}\end{array}$} & \multicolumn{2}{|c|}{$\mathbf{C}_{\mathrm{org}} \S$} & \multicolumn{2}{|c|}{$\mathbf{N} \$$} & \multirow[t]{2}{*}{$\mathrm{C}: \mathbf{N}$} \\
\hline & & $\mathrm{g} \mathrm{kg}^{-1}$ & $\begin{array}{l}\% \text { of } \\
\text { bulk }\end{array}$ & $\mathbf{g ~ k g}^{-1}$ & $\begin{array}{c}\% \text { of } \\
\text { bulk }\end{array}$ & \\
\hline & \multicolumn{6}{|c|}{ Flaesheim } \\
\hline \multicolumn{7}{|l|}{ Aeh } \\
\hline coarse sand & 0.8 & 1.8 & 0.1 & 0.2 & 0.4 & - \\
\hline medium sand & 33.1 & 0.4 & 0.9 & $<0.1$ & 0.9 & - \\
\hline fine sand & 49.3 & 0.6 & 2.1 & $<\mathbf{0 . 1}$ & 1.3 & - \\
\hline coarse silt & 8.0 & 2.7 & 1.5 & $<0.1$ & 2.1 & - \\
\hline medium silt & 2.2 & 102.5 & 16.1 & 2.7 & 15.3 & 38 \\
\hline fine silt & 2.0 & 263.8 & 37.6 & 5.7 & 29.4 & 46 \\
\hline clay & 1.5 & 393.7 & 42.0 & 10.9 & 42.2 & 36 \\
\hline DÓM & & & 1.0 & & & - \\
\hline \multirow{2}{*}{\multicolumn{7}{|c|}{ Bh }} \\
\hline & & & & & & \\
\hline coarse sand & 0.7 & 3.5 & 0.1 & $<0.1$ & $<0.1$ & - \\
\hline medium sand & 32.1 & 1.3 & 1.3 & $<0.1$ & 0.3 & - \\
\hline fine sand & 42.8 & 1.8 & 2.4 & $<0.1$ & 0.5 & - \\
\hline coarse silt & 7.1 & 4.6 & 1.0 & $<0.1$ & $<\mathbf{0 . 1}$ & - \\
\hline medium silt & 3.7 & 196.3 & 22.4 & 5.5 & 21.6 & 36 \\
\hline fine silt & 3.7 & 285.1 & 32.5 & 8.4 & 33.0 & 34 \\
\hline clay & 3.8 & 272.7 & 31.9 & 10.4 & 42.0 & 26 \\
\hline DOัM & 0.2 & 348.6 & 2.9 & 14.7 & - & 24 \\
\hline \multirow[t]{2}{*}{$\%$ recovery } & 94.1 & & 94.5 & & 97.5 & \\
\hline & \multicolumn{6}{|c|}{ Grafenwald } \\
\hline \multicolumn{7}{|l|}{ Aeh } \\
\hline coarse sand & 4.5 & 131.5 & 6.1 & 5.7 & 7.1 & 23 \\
\hline medium sand & 55.1 & 46.4 & 26.1 & 2.1 & 31.8 & 22 \\
\hline fine sand & 20.6 & 164.6 & 34.7 & 6.6 & 37.3 & 25 \\
\hline coarse silt & 6.5 & 62.9 & 4.2 & 2.4 & 4.2 & 26 \\
\hline medium silt & 5.5 & 294.9 & 16.6 & 11.2 & 16.9 & 26 \\
\hline fine silt & 2.1 & 288.4 & 6.2 & 12.8 & 7.4 & 23 \\
\hline clay & 1.6 & $\mathbf{3 1 1 . 3}$ & 5.1 & 18.2 & 8.0 & 17 \\
\hline DOัM & & & 0.7 & & - & \\
\hline$\%$ recovery & 95.9 & & 99.6 & & 112.7 & \\
\hline \multicolumn{7}{|l|}{ Bh } \\
\hline coarse sand & 3.1 & 1.0 & 0.2 & 0.4 & 2.1 & - \\
\hline medium sand & 61.9 & 0.5 & 1.9 & $<0.1$ & 1.1 & - \\
\hline fine sand & 13.4 & 3.5 & 2.8 & 0.4 & 9.2 & - \\
\hline coarse silt & 8.6 & 1.4 & 0.7 & 0.2 & 2.9 & - \\
\hline medium silt & 3.2 & 57.1 & 11.1 & 2.5 & 13.8 & 23 \\
\hline fine silt & 3.0 & 150.5 & 27,4 & 4.9 & 25.3 & 31 \\
\hline clay & 3.8 & 176.7 & $\mathbf{4 0 . 7}$ & 8.7 & 56.8 & 20 \\
\hline DOM】 & & & 3.1 & & & \\
\hline$\%$ recovery & 97.0 & & 87.9 & & 111.2 & \\
\hline
\end{tabular}

- Not determined.

$\uparrow$ AG-Boden (1994).

$¥$ Particle size separates obtained after ultrasonic dispersion as described in Materials and Methods.

\& Expressed as $\mathrm{g} \mathrm{kg}^{-1}$ bulk soil or size separate.

If Dissolved organic matter: after filtration the concentration of dissolved organic carbon was determined for the fraction $<0.45 \mu \mathrm{m}$ with an aliquot of the solution, and from this data \% of total organic carbon was calculated.

different pattern. In the clay to medium silt separates, carbon and nitrogen concentrations were similar (288.4 to $311.3 \mathrm{~g} \mathrm{C} \mathrm{kg}^{-1}$ ) to those discussed before. As a striking difference, the sand sized separates also had large concentrations of carbon and nitrogen, shifting the distribution of these elements between size separates. Here, sand size separates contributed the majority of carbon $(66.9 \%)$ and nitrogen $(76.2 \%)$, but $<20 \mu \mathrm{m}$ separates comprised only a third of the total soil carbon and nitrogen. The resulting $\mathrm{C}: \mathrm{N}$ ratios were different in two ways from those previously discussed. First, $\mathrm{C}: \mathrm{N}$ ratios of all separates are lower (17 to 26) and second, $\mathrm{C}: \mathrm{N}$ ratios do not decrease consistently from coarse to fine separates, only the separates $<20 \mu \mathrm{m}$ show this trend. Again, the parameters carbon and nitrogen concentration, resulting carbon and nitrogen distribution, and the $\mathrm{C}: \mathrm{N}$ ratios in the $>20 \mu \mathrm{m}$ separates differed from those commonly found in sandy soils. This suggests the presence of non-native organic matter in the $>20 \mu \mathrm{m}$ sized separates in the Aeh horizon of the Podzol Grafenwald. In the underlying Bhs horizon, however, these particles did not seem to be present. The non-native organic matter in the Aeh horizon of the Podzol Grafenwald was medium silt- to sand-sized. This was an unusually large diameter for airborne particles, suggesting a shorter transport distance or a lower density of these particles.

\section{Magnetic Susceptibility}

Thermal processes such as combustion often produce material high in magnetic susceptibility. A useful tool to assess the presence of industrial emissions and magnetic minerals in soils can be the measurement of magnetic susceptibility (Dearing et al., 1995; Strzyszcz, 1993). As an advantage compared with wet chemical analysis and spectroscopic techniques (e.g., NMR), the measurement of magnetic susceptibility is less time consuming and relatively inexpensive and thus can be applied to large numbers of samples. On the other hand, this measurement can provide only limited information on the quantity and sources of industrial emissions.

In Table 1 we report mass-specific magnetic susceptibility. The organic layers increased consistently in magnetic susceptibility from $\mathrm{L}$ to $\mathrm{Oh}$ horizons (4 to $109 \times$ $10^{-8} \mathrm{~m}^{3} \mathrm{~kg}^{-1}$ ) and were similar in both Podzols. Published data on magnetic susceptibility of organic horizons is sparse. Histic horizons of Bavarian soils tended to be lower in magnetic susceptibility (Stanjek, personal communication, 1999), while in Polish national parks close to industrial regions magnetic susceptibilities of $\mathrm{L}$, Of and Oh horizons were larger (108 to $1940 \times 10^{-8}$ $\mathrm{m}^{3} \mathrm{~kg}^{-1}$; Strzyszcz, 1991, 1993). Also, organic layers in English soils probably comprising fly ash were higher (530 to $480 \times 10^{-8} \mathrm{~m}^{3} \mathrm{~kg}^{-1}$ ) in magnetic susceptibility (Dearing et al., 1995). Although mass-specific magnetic susceptibility tends to be higher and more variable in organic layers than in mineral horizons, our results suggest that both Podzols contained magnetically susceptible material in their organic horizons, which probably originated from industrial emissions.

The mineral horizons showed striking differences between the two Podzols. The A and B horizons of the Podzol Flaesheim were uniformly low in magnetic susceptibility $\left(1 \times 10^{-8} \mathrm{~m}^{3} \mathrm{~kg}^{-1}\right)$. The same was true for the Podzol Grafenwald, except for the Aeh horizon $\left(81 \times 10^{-8} \mathrm{~m}^{3} \mathrm{~kg}^{-1}\right)$ and for the Ae horizon $\left(4 \times 10^{-8}\right.$ $\mathrm{m}^{3} \mathrm{~kg}^{-1}$ ). The magnetic susceptibility of the Aeh was extremely high compared with common values for natural $\mathrm{A}$ and $\mathrm{B}$ horizons, often varying around $1 \times 10^{-8}$ $\mathrm{m}^{3} \mathrm{~kg}^{-1}$ (Dearing et al., 1996). Natural pedogenetic processes cannot explain the presence of such a highly magnetically susceptible material in the studied Podzols, suggesting the presence of industrial emissions in the Aeh horizon and to a lesser degree in the Ae horizon 
of Podzol Grafenwald. These emissions did not affect the B horizons, supporting previous results from elemental analysis. Contrasting, in the Podzol Grafenwald the magnetic susceptibility was uniformly low for all mineral horizons, indicating the absence of emissions. This apparent difference probably could be explained by less-intense intermixing of humus with mineral matter, as indicated by the humus types. The Podzol Flaesheim had a thick layer of slowly turning-over mor-type humus, whereas the Podzol Grafenwald had a thin layer of more rapidly decaying moder-type humus.

\section{Reflected Light Microscopy of the Podzol Grafenwald}

As discussed before, we suspected the floating fraction obtained from the Aeh horizon of the Podzol Grafenwald to contain a major proportion of the carbonaceous particles. To identify these particles, we investigated this fraction by reflected light microscopy (Fig. 2). Additionally, we examined samples from the Oh horizon from the Podzol Flaesheim.

Due to the optical properties of the immersion oil, quartz grains were not visible. Most of the visible particles (approximately $95 \%$ of the area) were organic matter and mineral particles with inclusions of organic matter. Major components were mineral particles in the shape of spheres (20 to $150 \mu \mathrm{m}$ in length). Encapsulated in these spheres were coal particles, which could be attributed to different maceral groups. The coal particles were mainly fusinite (Fig. 2a) and other inertinite particles, which is a fossil charcoal probably formed in the Carboniferous swamps. These naturally charred organic particles often have a highly aromatic structure. The more thick-walled spheres included vitrinite particles, which have been thermally altered by industrial coking
(Fig. 2c). Vitrinite is a typical component of bituminous coal. These mineral spheres contribute the majority to the visible particles and developed during combustion at temperatures of $1500^{\circ} \mathrm{C}$, according to a morphological char classification system (Bailey et al., 1990).

Less abundant were particles of highly volatile bituminous coal (20 to $50 \mu \mathrm{m}$ in length; Fig. 2d). These coal particles include all maceral groups and have not undergone thermal alterations, such as combustion or coking. Some coal particles display oxidized rims, probably indicating a longer residence time in the soil. Least abundant were coke particles (100 to $250 \mu \mathrm{m}$; Fig. $2 \mathrm{~b}$ ) probably originating from metallurgic processes. This conclusion was supported by the finding of highly reflective, probably metallic particles (35- $\mu \mathrm{m}$ diameter; Fig. $2 \mathrm{e})$. The presence of metallic and mineral particles formed by combustion and metallurgical processes probably could explain the high magnetic susceptibility of this horizon. Similar particles were observed in organic layer $\mathrm{Oh}$ of the Podzol Flaesheim (not shown here). The majority of the visible particles were small, highly reflective organic particles ( 2 to $10 \mu \mathrm{m}$ diameter), which probably are thermally altered organic matter. Less abundant were coal particles (mainly vitrinite) and cenospheres. Thus, carbonaceous particles in the 20 - to $200-\mu \mathrm{m}$ range dominated the floating fraction and probably produced the uncommon pattern of carbon and nitrogen in the particle-size fractions. The fact that these particles are larger than common mineral airborne particles could be explained by porous structure and low particle density.

\section{Carbon-13 Magic Angle Spinning Nuclear Magnetic Resonance Spectroscopy}

Carbon-13 magic angle spinning nuclear magnetic resonance spectroscopy is a nondestructive technique that
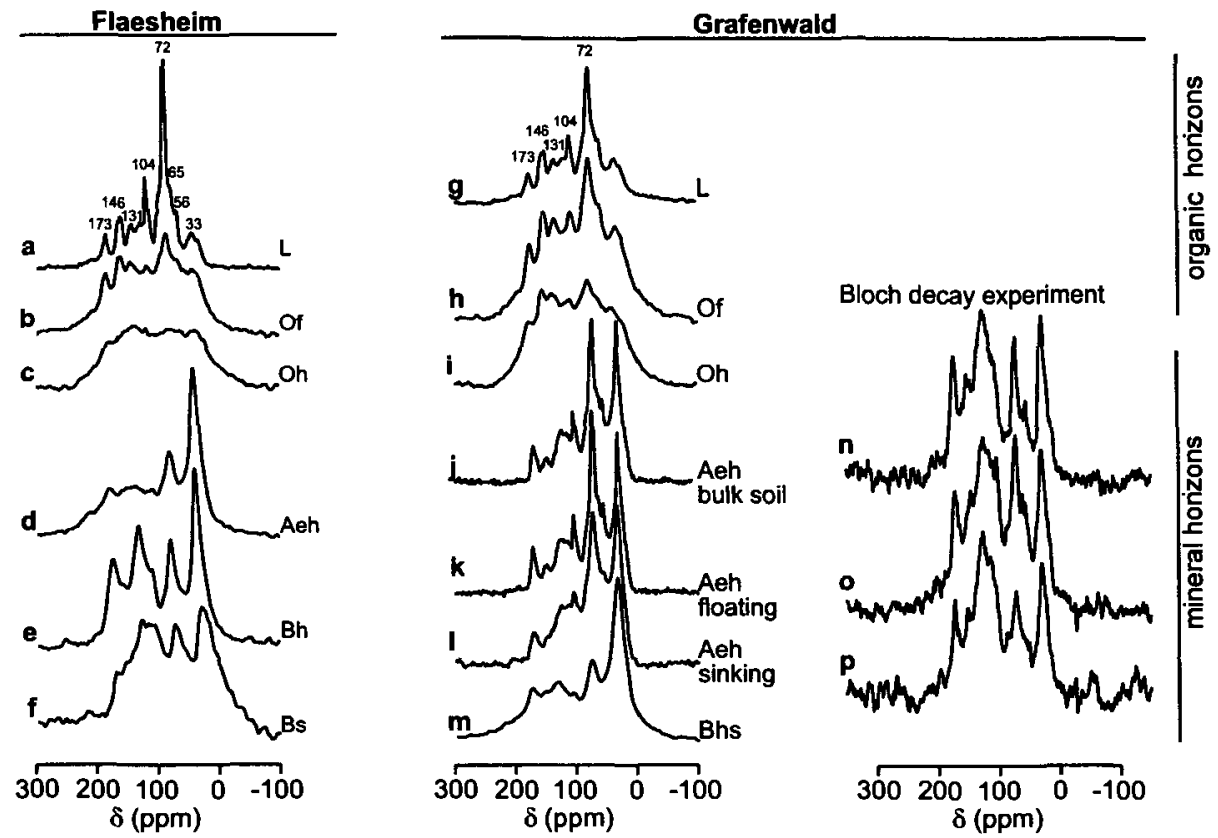

Fig. 2. Carbon-13 Bloch decay and cross-polarization solid-state nuclear magnetic resonance spectra of the different horizons from the Podzol Grafenwald and Flaesheim. The spectra of the mineral horizons ( $d-f$ and $j-p$ ) were treated with hydrofluoric acid, as described in the Materials and Methods section. 
can yield quantitative information on the average chemical composition of soil organic matter without chemical pretreatments. This technique, however, is time consuming and relatively expensive compared with standard wet chemical analysis and thus cannot be applied to large sample sets routinely.

First, we carried out ${ }^{13} \mathrm{C}$ solid-state NMR spectroscopy with CP experiments. The samples from the organic horizons (L, Of, Oh) were reasonably rich in organic carbon to probably yield ${ }^{13} \mathrm{C}$ spectra with small signal to noise ratios. Samples from mineral horizons, however, were treated with hydrofluoric acid (HF 10\%) to increase the resolution of the spectra. The treatment considerably decreased the content of minerals and paramagnetics, without major alterations of the chemical structure of organic matter, and was successfully applied to samples containing paramagnetic compounds from anthropogenic sources (Schmidt et al., 1997b).

Spectroscopy revealed rather similar spectra for organic layers from both Podzols (Fig. 3a,b,c,g,h,i, Table 4). The chemical shift assignments (ppm) are given in Table 2. The spectra of the L horizons (Fig. 3a,g) from both Podzols were dominated by signals in the $\mathrm{O}$-alkyl region (60 to $110 \mathrm{ppm}$ ) indicating the presence of polysaccharide, alcoholic, and ether structures. Signals at 72 and $75 \mathrm{ppm}$ corresponded with ring carbon C-5 and $\mathrm{C}-2$, resonances at $104 \mathrm{ppm}$ were attributed to anomeric C-1 carbon, and the shoulder at 65 ppm to C-6 carbon in polysaccharides. Signals of methoxyl carbon may be indicated by a weak shoulder at $56 \mathrm{ppm}$. Signals at 33 ppm in the alkyl-C region ( 45 to $-10 \mathrm{ppm}$ ) could be attributed to methylene carbon. Shoulders at 16, 21, and $26 \mathrm{ppm}$ revealed the presence of methyl and acetyl groups terminal to alkyl chains. Several signals in the $\mathrm{sp}^{2}$-hybridized $\mathrm{C}$ region (160 to $110 \mathrm{ppm}$ ) indicated the presence of protonated and C-substituted aryl carbon (110 to $130 \mathrm{ppm}$ ) and $\mathrm{O}$-substituted aromatic carbon (140 to $160 \mathrm{ppm})$, typically present in lignin, cutin, and condensed tannin (Preston et al., 1997). In the carboxyl $\mathrm{C}$ region (220 to $160 \mathrm{ppm}$ ), broad signals of carboxyl carbon, amide, and ester structures could be observed (Preston et al., 1982; Preston and Schnitzer, 1984). For both Podzols, polysaccharide signals typically decreased with depth, indicating an increasing decomposition of plant material (Kögel-Knabner, 1993). Despite large carbon concentrations of the $\mathrm{Of}$ and $\mathrm{Oh}$ horizons from both Podzols ( $\geq 258 \mathrm{~g} \mathrm{~kg}^{-1}$ ) the resulting spectra (Fig. $3 b, c, h, i)$ showed low resolutions, which was very uncommon compared with spectra from organic layers of other natural forest soils (Kögel-Knabner, 1993). Low resolutions could be explained by high magnetic susceptibilities, probably due to the presence of paramagnetic material from industrial carbonaceous particles, as discussed before. Consequently, this was an additional indication for the presence of non-native matter in the organic layers of both Podzols.

The ${ }^{13} \mathrm{C}$ CPMAS NMR experiment on the sample from the Flaesheim Aeh horizon (Fig. 3d) yielded a spectrum dominated by a signal assignable to alkyl $\mathrm{C}$ ( $37 \%$ of the total signal intensity), while $\mathrm{O}$-alkyl $\mathrm{C}$ contributed only $30 \%$. Also, the Aeh horizon of the Podzol
Grafenwald (Fig. 3j) showed high signal intensities in the alkyl $\mathrm{C}$ region, but signals for $\mathrm{O}$-alkyl $\mathrm{C}$ dominated the spectrum $(40 \%)$. These signals could indicate the presence of larger proportions of plant material. On mixing with water, this Aeh horizon formed a floating and a sinking fraction, as discussed in the Materials and Methods section. The spectra of these two subfractions (Fig. 3k,l,m) were almost identical to the bulk soil, suggesting a fairly similar chemical structure for both samples. In the underlying Bhs horizon (Fig. $3 \mathrm{~m}$ ), signals for O-alkyl C were lower (30\%) than in the Aeh horizon, again with a dominant signal in the alkyl $\mathrm{C}$ region $(33 \%)$. This also was true for the Bh horizons of Podzol Flaesheim (Fig. 3e), except that it yielded higher relative intensities in the aromatic $\mathrm{C}$ region $(29 \%)$. This confirmed previous observations that $\mathrm{Bh}$ samples contained appreciably more aromatic $\mathrm{C}$ than Bhs horizons (Skjemstad et al., 1992). All the presented spectra here generally were in the range observed for other natural Podzols (Hempfling et al., 1987; Skjemstad et al., 1992). However, indications for the presence of carbonaceous particles could not be obtained by ${ }^{13} \mathrm{C}$ solid-state NMR spectroscopy using $\mathrm{CP}$. This was in sharp contrast to our observations from reflected light microscopy, where the floating fraction contained large proportions of charred organic particles and bituminous coal.

A possible explanation for this obvious discrepancy could be the type of ${ }^{13} \mathrm{C}$ NMR experiment we used. Char and bituminous coal are highly condensed aromatic structures. In CP experiments, the polarization energy for carbon nuclei is transferred via hydrogen nuclei with an efficiency depending on the proximity of these nuclei. Consequently, the carbon nuclei in condensed structures are underestimated by CP experiments (Alemany et al., 1983; Snape et al., 1989). To detect such carbons we performed Bloch decay experiments, in which carbon nuclei were polarized directly. However, pulse delay had to be adjusted according to the relaxation properties of the carbon, resulting in long recycle times. Typically, $>40 \mathrm{~s}$ would be required in Bloch decay experiments and it would take several days to obtain a single spectrum that would still give a poor signal to noise ratio. Long recycle times limit the number of samples that can be analyzed by Bloch decay experiments. We focused with Bloch decay experiments on the Aeh horizon and its subfractions, because previous experiments indicated the presence of carbonaceous particles, and it was sufficiently high in organic carbon content to obtain reasonably resolved spectra.

The Bloch decay ${ }^{13} \mathrm{C}$ NMR spectra of the bulk Aeh horizon and its floating and sinking subfraction (Fig. 3n,o,p; Table 4) showed smaller signal to noise ratios than those obtained by CP experiments, due to the lower number of scans. All spectra shared two facts. They were almost identical for bulk soil and floating and sinking fractions, as observed also for the CP spectra. All spectra are dominated by peaks centered around $130 \mathrm{ppm}$ (33 to $38 \%$ ), which was a striking difference to results from the CP experiments (18 to 19\%). These higher intensities in Bloch decay experiments indicated the presence of condensed aromatic structures, which 

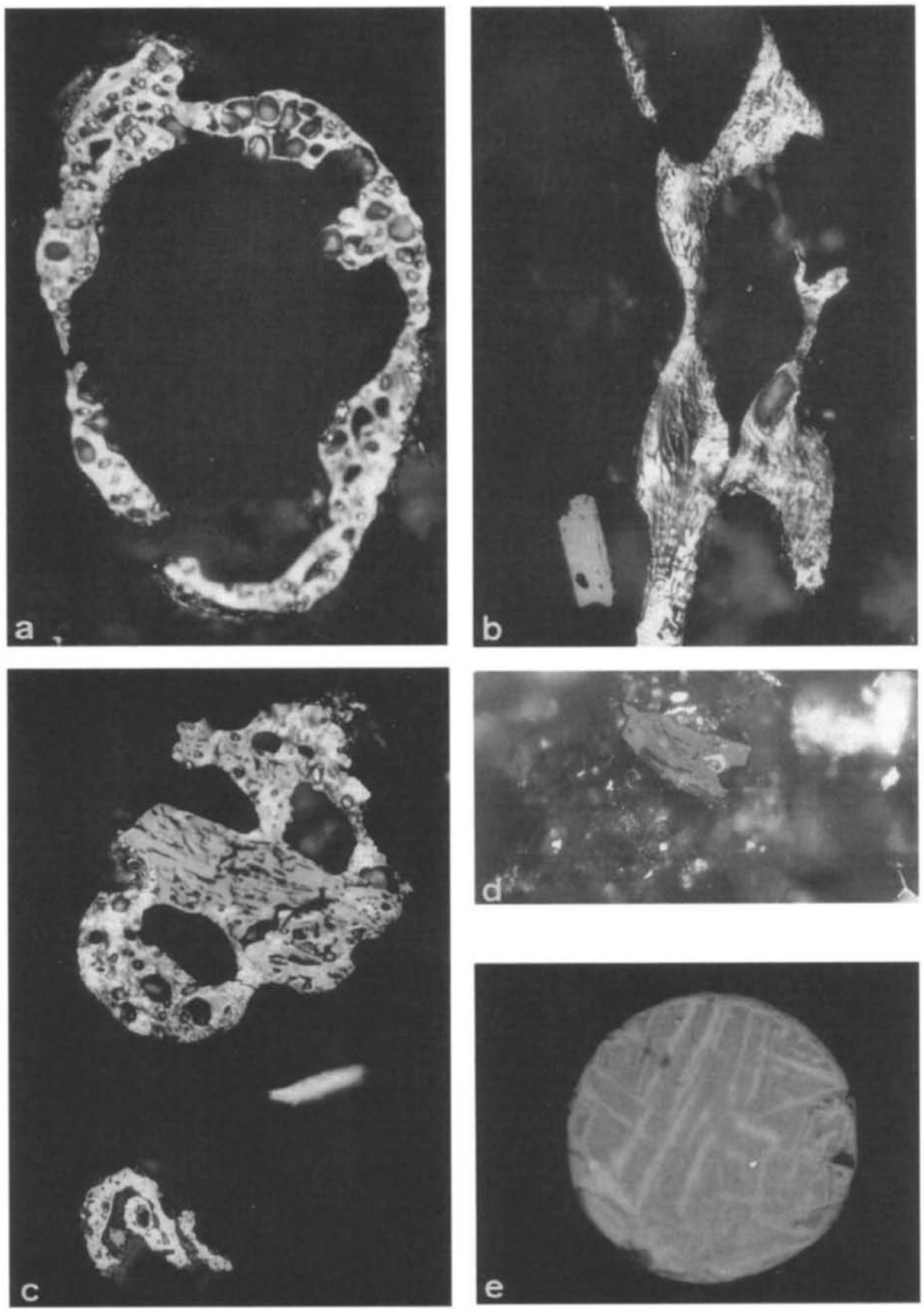

Fig. 3. Photomicrographs of the floatable fraction of the Aeh horizon from Podzol Grafenwald: (a) char sphere with fusinite (maximum diameter $200 \mu \mathrm{m}$ ), (b) coke particle (length $230 \mu \mathrm{m}),(c)$ char sphere with vitrinite (maximum diameter $100 \mu \mathrm{m})$, (d) bituminous coal (length $45 \mu \mathrm{m}$ ), and (e) metallic particle (diameter $35 \mu \mathrm{m})$. 
Table 4. Relative areas of peaks in ${ }^{13} \mathrm{C}$ MAS NMR spectra from both Podzols. Both cross polarization and bloch decay technique (data in parentheses) have been applied.

\begin{tabular}{|c|c|c|c|c|}
\hline Sample & Carboxylic C & Aromatic C & O-alkyl C & Alkyl C \\
\hline & - $\%$ & of total signal & intensity $\dagger$ & - \\
\hline \multicolumn{5}{|l|}{ Flaesheim } \\
\hline $\mathbf{L}$ & 11 & 24 & $\mathbf{5 3}$ & 12 \\
\hline of & 20 & 38 & 26 & 14 \\
\hline Oh & 15 & 27 & 34 & 23 \\
\hline Aeh & 15 & 19 & 30 & 37 \\
\hline Bh & 14 & 29 & 29 & 28 \\
\hline Bs & 10 & 25 & 34 & 28 \\
\hline \multicolumn{5}{|l|}{ Grafenwald } \\
\hline L & 6 & 24 & 52 & 18 \\
\hline of & 8 & 26 & 44 & 22 \\
\hline Oh & 12 & 29 & 38 & 21 \\
\hline Aeh-bulk & 5 (16) & $19(37)$ & $46(29)$ & 32 (19) \\
\hline -floatable fraction & 7 (14) & $18(33)$ & $46(35)$ & 29 (18) \\
\hline -non-floatable & $6(13)$ & 18 (38) & $44(30)$ & 31 (18) \\
\hline Bhs & 15 & 20 & 30 & 33 \\
\hline
\end{tabular}

$\dagger$ Data in \% of total signal intensity (alkyl C -10 to $45 \mathrm{ppm}, \mathrm{O}$-alkyl C 45 to $110 \mathrm{ppm}$, aromatic C 110 to $160 \mathrm{ppm}$, carboxyl C 160 to $220 \mathrm{ppm}$ ).

were invisible in previous $\mathrm{CP}$ experiments. This result confirmed previous assumptions that thermally altered carbonaceous particles form major proportions of the organic matter in the Aeh horizon of the Podzol Grafenwald.

\section{CONCLUSIONS}

We were able to identify airborne carbonaceous particles in two Podzols under forest adjacent to the formerly highly industrialized German Ruhr-area. We combined a suite of complementary methods (i.e., elemental analysis, reflected light microscopy, magnetic measurement, and ${ }^{13} \mathrm{C}$ MAS NMR spectroscopy using both $\mathrm{CP}$ and Bloch decay experiments). It seemed that previous studies of industrial emissions in soils were sparse, mainly focusing on organic horizons, and that this was the first time that carbonaceous particles have been identified and chemically characterized in mineral horizons. These particles were not visible macroscopically and were char from fossil fuel combustion, coke from coking plants or steel smelters, and coal dust. They were probably released some years to decades ago and traveled by atmospheric transport at least $10 \mathrm{~km}$ (Grafenwald site) or $30 \mathrm{~km}$ (Flaesheim site) before they eventually settled. These particles were still present in the organic horizons of both soils. In the Podzol Grafenwald, carbonaceous particles also were present in the underlying mineral horizons, probably due to more intense intermixing, typical for moder-type humus. From the large distance (about 10 to $30 \mathrm{~km}$ ) between the nearest industrial sources and the Podzols, we conclude that carbonaceous particles could be ubiquitous in soils of industrialized regions and may not necessarily be restricted to areas directly neighboring industrial plants. Further, we hypothesize that carbonaceous particles in soils often could have remained undetected, due to lower concentrations than in the Podzols studied here.

It can be an analytical challenge to detect the presence of carbonaceous particles in soils. These particles can be macroscopically invisible and larger carbon and nitrogen concentrations indicate their presence unambig- uously only if concentrations are significantly larger than the natural background. The high magnetic susceptibility of materials altered by industrial thermal processes may serve as a screening for carbonaceous particle emissions in soils. Reflected light microscopy can serve as a powerful and easily available technique to elucidate the morphology, sources, and in favorable cases, temperature of formation of the carbonaceous particles. Cross-polarization is a standard technique applied in ${ }^{13} \mathrm{C}$ MAS NMR spectroscopy of soil organic matter. However, the presence of carbonaceous particles from industrial coal processing may not be detectable in soils due to its highly condensed structure and high concentrations of interfering paramagnetic compounds. Treatment with hydrofluoric acid can reduce paramagnetics and application of the Bloch decay technique is essential to detect the presence of carbonaceous particles with highly condensed aromatic structures.

The presence of carbonaceous particles in soils of industrialized areas poses some questions on possible particle influence on soil properties. These particles may affect physical soil properties (water holding capacity, structural stability), chemical soil properties $(\mathrm{pH}$, C-content, cation exchange capacity, sorption capacity), and biological activity. As examples, coal and its burned residues may improve the water holding capacity, influence the soil sorptive capacity for organic pollutants, and stress microbial populations and their activities (Kile et al., 1995; Schutter and Fuhrman, 1999). However, potential effects of atmospheric deposition of carbonaceous particles at the field scale are only poorly understood.

Our results suggest that the atmospheric input of charred organic particles from coal processing industries may be quantitatively important in many soils of industrialized regions.

\section{ACKNOWLEDGMENTS}

This work was financially supported by the Deutsche Forschungsgemeinschaft (Ko 1035/6-1 and 2) and the Deutscher Akademischer Austauschdienst (Ref. 315, D/94/ 16993). For help during site selection, we thank H. Wolfsperger (Geologisches Landesamt of NRW, Krefeld) and J.M. Wipf, E. Kleibrink, W. Matheis, and G. Klesen (Kommunalverband Ruhrgebiet, Essen). Experimental assistance was provided by W. Gosda and G. Wilde (Ruhr-Universität Bochum) and figures of the spectra were prepared by E. Schuhbauer (Technische Universität München). Magnetic susceptibility was measured by C. Rumpel (Brandenburgische Technische Universität Cottbus). We thank A. Davis (Pennsylvania State University) and F. Laggoun-Défarge (CNRS, Orléans) for assistance in obtaining reflected light microscopic information. H. Stanjek (Technische Universität München) supported this study with his expertise in magnetic measurements.

\section{REFERENCES}

AG-Boden, 1994. Bodenkundliche Kartieranleitung. E. Schweizerbart'sche Verlagsbuchhandlung, Stuttgart, Germany.

Alemany, L.B., D.M. Grant, R.J. Pugmire, T.D. Alger, and K.W. Zilm. 1983. Cross polarization and magic angle sample spinning NMR spectra of model organic compounds. 2. Molecules of low or remote protonation. J. Am. Chem. Soc. 105:2142-2147.

Bailey, J.G., A. Tate, C.F.K. Diessel, and T.F. Wall. 1990. A char 
morphology system with applications to coal combustion. Fuel 69:225-239.

Blaurock, H. 1990. Walderhaltung im Ruhrgebiet. Allg. Forstzeitschrift 22-23:534-536.

Christensen, B.T. 1992. Physical fractionation of soil and organic matter in primary particle size and density separates. Adv. Soil Sci. 20:1-90.

Cornelsen, R. 1991. Atlas für Nordrhein-Westfalen. Cornelsen, Berlin, Germany.

Dearing, J.A., K.L. Hay, S.M.J. Baban, A.S. Huddleston, E.M.H. Wellington, and P.J. Loveland. 1996. Magnetic susceptibility of soil: An evaluation of conflicting theories using a national dataset. Geophysical Journal International 127:728-734.

Dearing, J.A., J.A. Lees, and C. White. 1995. Mineral magnetic properties of acid gleyed soils under oak and Corsican Pine. Geoderma 68:309-319.

Elbers, G., T. Zang, and M. Buck. 1990. Ruß-Immissionsmessung im Einflußbereich des Kraftfahrzeugverkehrs. Luft 50:439-443.

FAO. 1994. FAO-Unesco soil map of the world, revised legend. FAO, Rome.

Gee, G.W. and J.W. Bauder. 1986. Particle size analysis. p. 383-411. In A. Klute (ed.) Methods of soil analysis. I. Physical and mineralogical methods. 2nd ed. Agron. Monogr. 9. ASA, SSSA, Madison, WI.

Hedges, J.I., and J.M. Oades. 1997. Comparative organic geochemistries of soils and sediments. Org. Geochem. 27:319-361.

Hempfling, R., F. Ziegler, W. Zech, and H.-R. Schulten. 1987. Litter decomposition and humification in acidic forest soils studied by chemical degradation, IR and NMR spectroscopy and pyrolysis field ionization mass spectrometry. Z. Pflanzenernaehr. Bodenkd. 150:179-186.

Karls, J.F., and E.R. Christensen. 1998. Carbon particles in dated sediments from Lake Michigan, Green Bay, and tributaries. Environ. Sci. Technol. 32:225-231.

Kile, D.E., C.T. Chiou, H. Zhou, H. Li, and O. Xu. 1995. Partition of nonpolar organic pollutants from water to soil and sediment organic matters. Environ. Sci. Technol. 29:1401-1406.

Knicker, H., 1993. Quantitative ${ }^{15} \mathrm{~N}$ und ${ }^{13} \mathrm{C}$-CPMAS-Festkörper und Flüssigkeits-NMR-Spektroskopie an Pflanzenkomposten und natürlichen Böden. Ph.D. thesis. University of Regensburg, Regensburg, Germany.

Kögel-Knabner, I. 1993. Biodegradation and humification processes in forest soils. p. 101-137. In J.-M. Bollag and G. Stotzky (ed.) Soil biochemistry. Marcel Dekker, New York.

Lichtfouse, E., H. Budzinski, P. Garrigues, and T.I. Eglinton. 1997. Ancient polycyclic aromatic hydrocarbons in modern soils: ${ }^{13} \mathrm{C},{ }^{14} \mathrm{C}$ and biomarker evidence. Org. Geochem. 26:353-359.

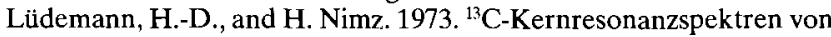
Ligninen, 2. Makromol. Chem. 175:2409-2422.

MURL. 1989. Luftreinhaltung in NRW. Eine Erfolgsbilanz der Luftreinhalteplanung 1975-1988. Bonner Universitätsdruckerei, Bonn, Germany.

Preston, C.M., B.S. Rauthan, C.A. Rodger, and J.A. Ripmeester. 1982. A hydrogen-1, carbon-13 and nitrogen-15 nuclear magnetic resonance study of p-benzoquinone polymers incorporating amino nitrogen compounds ("synthetic humic acids"). Soil Sci. 134: 277-293.

Preston, C.M., and M. Schnitzer. 1984. Effects of chemical modifications and extractants on the C-13 NMR spectra of humic materials. Soil Sci. Soc. Am. J. 48:305-311.

Preston, C.M., J.A. Trofymow, B.G. Sayer, and J. Niu. $1997 .{ }^{13} \mathrm{C}$ nuclear magnetic resonance spectroscopy with cross-polarization and magic-angle spinning investigation of the proximate analysis fractions used to assess litter quality in decomposition studies. Can. J. Bot. 75:1601-1613.

Rau, J.A., and M.A.K. Khalil. 1993. Anthropogenic contributions to the carbonaceous content of aerosols over the Pacific Ocean. Atmos. Environ. 27A:1297-1307.

Rehfuess, K. 1990. Waldböden, Entwicklung, Eigenschaften und Nutzung. Parey, Hamburg, Germany.

Rumpel, C., H. Knicker, I. Kögel-Knabner, and R.F. Hüttl. 1998. Airborne contamination of immature soil (Lusation mining district) by lignite-derived materials: Its detection and contribution to the soil organic matter budget. Water Air Soil Pollut. 105:481-492.

Schaefer, J., and E.O. Stejskal. 1976. Carbon-13 nuclear magnetic resonance of polymers spinning at magic angle. J. Am. Chem. Soc. 98:1031-1032

Schmidt, M.W.I., H. Knicker, P.G. Hatcher, and I. Kögel-Knabner. 1996. Impact of brown coal dust on the organic matter in particlesize fractions of a Mollisol. Org. Geochem. 25:29-39.

Schmidt, M.W.I., H. Knicker, P.G. Hatcher, and I. Kögel-Knabner. 1997a. Does ultrasonic dispersion and homogenization by ball milling change the chemical structure of organic matter in geochemical samples?-A CPMAS ${ }^{13} \mathrm{C}$ NMR study with lignin. Org. Geochem. 26:491-496.

Schmidt, M.W.I., H. Knicker, P.G. Hatcher, and I. Kögel-Knabner. 1997b. Improvement of ${ }^{13} \mathrm{C}$ and ${ }^{15} \mathrm{~N}$ CPMAS NMR spectra of bulk soils, particle size fractions and organic material by treatment with $10 \%$ hydrofluoric acid. Eur. J. Soil Sci. 48:319-328.

Schmidt, M.W.I., and A.G. Noack. 2000. Black carbon in soils and sediments: Analysis, distribution, implications and current challenges. Global Biogeochem. Cycles (in press).

Schmidt, M.W.I., C. Rumpel, and I. Kögel-Knabner. 1999a. Evaluation of an ultrasonic dispersion procedure to isolate primary organomineral complexes from soils. Eur. J. Soil Sci. 50:87-94.

Schmidt, M.W.I., C. Rumpel, and I. Kögel-Knabner. 1999b. Particle size fractionation of soil containing coal and combusted particles. Eur. J. Soil Sci. 50: 515-522.

Schultz, E. 1993. Size-fractionated measurement of coarse black carbon particles in deposition samples. Atmos. Environ. 27A: 1241-1249.

Schutter, M.E., and J.J. Fuhrman. 1999. Microbial responses to coal fly ash under field conditions. J. Environ. Qual. 28:648-652.

Shindo, H. 1991. Elementary composition, humus composition, and decomposition in soil of charred grassland plants. Soil Sci. Plant Nutr. 37:651-657.

Shneour, E. 1966. Oxidation of graphite carbon in certain soils. Science 155:991-992.

Skjemstad, J.O., A.G. Waters, J.V. Hanna, and J.M. Oades. 1992. Genesis of podzols on coastal dunes in Southern Queensland. IV. Nature of the organic fraction as seen by $13 \mathrm{C}$ nuclear magnetic resonance spectroscopy. Aust. J. Soil Res. 30:667-681.

Snape, C.E., D.E. Axelson, R.E. Botto, J.J. Delpuech, P. Tekely, B.C. Gerstein, M. Pruski, G.E. Maciel, M.A. Wilson. 1989. Quantitative reliability of aromaticity and related measurements on coals by ${ }^{13} \mathrm{C}$ n.m.r. A debate. Fuel 68:547-560.

Strzyszcz, Z. 1991. Ferromagnetism of soils in some Polish national parks. Mitteilungen der Deutschen Bodenkundlichen Gesellschaft 61:1119-1122.

Strzyszcz, Z. 1993. Magnetic susceptibility of soils in the areas influenced by industrial emissions. p. 255-269. In R. Schulin (ed.) Soil monitoring. Early detection and surveying of soil contamination and degradation. Proceedings of the Centro Stefano Franscini Ascona. Birkenhöuser Verlag, Basel, Switzerland.

Thompson, R., and F. Oldfield. 1986. Environmental magnetism. Allen \& Unwin, London.

Wik, J., and I. Renberg. 1996. Environmental records of carbonaceous fly-ash particles from fossil-fuel combustion. A summary. J. Paleolimnol. 15:193-206.

Wilson, M.A. 1987. NMR techniques and applications in geochemistry and soil chemistry. Pergamon Press, Oxford, UK. 